Pecvnia, 2 (2006), pp. 23-63

\title{
Evolución del proceso de regulación bancaria hasta Basilea-2: Origen, características y posibles efectos
}

\author{
Cristina Gutiérrez López \\ José Miguel Fernández Fernández \\ José Miguel Fernández Fernández
}

\begin{abstract}
El sistema financiero se prepara para afrontar los retos derivados del Nuevo Acuerdo de Capitales aprobado en 2004, que viene a culminar un proceso de regulación financiera definido por la exigencia de capital como expresión de la solvencia. Esta evolución ha dado respuesta a la actividad de los intermediarios financieros, los cambios debidos a la globalización e innovación financiera, y los nuevos riesgos que han surgido en consecuencia. Además, se incorpora la supervisión a través del regulador y de la disciplina de mercado.

El artículo resume las características de la regulación de capital bancario, hasta llegar al capital ajustado al riesgo que caracteriza los Acuerdos elaborados desde Basilea, para detallar después los contenidos del Nuevo Acuerdo, sus fortalezas y debilidades, así como sus posibles efectos.
\end{abstract}

Palabras clave: regulación bancaria, solvencia, capital, Basilea-2, prociclicidad.

(1)


Evolución del proceso de regulación bancaria hasta

Basilea2: Origen, características y posibles efectos

\section{INTRODUCCIÓN}

A finales de 2006 se espera el inicio de la implantación del Nuevo Acuerdo de Capitales de Basilea (Basilea-2), dejando para un año más tarde la utilización de los más avanzados enfoques de medición de riesgos, tras un previsible período de análisis del impacto de las nuevas reglas de capital y la coexistencia con las anteriores. Este nuevo Acuerdo, que sustituye a la regulación internacional de 1988, es el punto y seguido del proceso de regulación bancaria a través de la exigencia de mantener un capital mínimo para garantizar la solvencia de los intermediarios financieros ${ }^{1}$. El largo proceso de redacción del Acuerdo deja abierta la posibilidad de nuevas modificaciones, en espera de que los modelos finalmente aplicados por las entidades y que demuestren ser las "mejores prácticas" bancarias se conviertan en un estándar.

La regulación impuesta por las autoridades monetarias sobre el sector obedece a dos objetivos: instrumentar la política económica y reforzar la solvencia de las entidades y del sistema. Una de las razones intuitivas que parecen soportar esa necesidad de regular la actividad bancaria más que cualquier otra está implícitamente relacionada con el riesgo, pues las entidades financieras asumen riesgos muy superiores a los de cualquier otra empresa, dadas las características de su actividad. Además, su especial sensibilidad al ciclo económico condiciona su tratamiento. Así, una fase recesiva se traduce habitualmente en un incremento de la morosidad, con la consiguiente repercusión sobre la estructura de costes. Por el contrario, atravesar una fase expansiva del ciclo conlleva una expansión del crédito.

Actualmente la importancia del capital bancario radica en su expresión de solvencia. La regulación a través de requisitos de capital obedece a la intención de generar una "red de seguridad" no sólo para los depositantes sino también para el gobierno, que con la existencia del seguro de depósitos se convierte en el mayor acreedor no-asegurado de los bancos. Además, permite proteger a la economía de las externalidades negativas que suponen las quiebras bancarias, sobre todo en forma de riesgo sistémico (Berger et al. 1995).

1 En adelante no se distinguirá entre los diferentes tipos de intermediarios financieros, esto es, en el caso español, bancos, cajas de ahorro o cooperativas de crédito, pese a que existan diferencias en los objetivos sociales o las limitaciones en su actividad operativa. Por tanto, se emplearán indistintamente "bancos" o "entidades financieras", por ejemplo. 
La regulación bancaria se ha desarrollado e implementado tradicionalmente a un nivel local o nacional. En 1913 la Federal Reserve Act imponía requisitos mínimos de capital a los bancos para ser miembros de la Reserva Federal. La Banking Act de 1933 ("Glass-Steagall Act" debido al nombre de su impulsor), diseñada para restablecer la estabilidad financiera del país durante la Gran Depresión a través de la creación de un seguro de depósitos y la separación de la banca comercial y banca de inversiones, ha marcado la estructura de banca norteamericana, restringiendo notablemente la actividad desarrollada por los bancos comerciales.

Pese a este precedente, la toma de conciencia de que el negocio bancario es internacional ha surgido tras la quiebra y/o graves dificultades atravesadas por importantes bancos ${ }^{2}$, poniendo de manifiesto que la ausencia de una cooperación internacional puede incluso amplificar los efectos de los problemas individuales. Además, la integración financiera internacional requiere de una coordinación o ajuste internacional, dado que las disparidades entre normativas de los distintos países provocan diferencias en los costes, que pueden favorecer a unas entidades en detrimento de otras, es decir, efectos sobre la competitividad.

El artículo se estructura como sigue: la sección segunda resume, desde el punto de vista teórico, los fundamentos de la regulación bancaria con requisitos de capital, a partir de las significatividad y características del sector bancario en el sistema financiero, que aportan argumentos para acometer tal regulación, sin olvidar las posturas en contra. Este proceso nos conduce a la definición de un sistema de capital sensible al riesgo sobre el que se sostiene la regulación internacional vigente. En este contexto, la sección tercera analiza las características del Acuerdo de Capitales aprobado en 1988, así como las debilidades que motivaron su reforma y el proceso que ha llevado al actual Acuerdo de Basilea-2. La estructura del esquema actual, que será aplicado en un corto plazo, es posteriormente comentada, sin olvidar sus posibles consecuencias, especialmente respecto a los efectos procíclicos que podría generar. Finalmente, la sección cuarta concluye.

2 Destacan los casos del banco alemán Bankhaus Herstatt (1974) y el Banco Ambrosiano (1982), al ser previos al inicio de la regulación internacional (1988), y con posterioridad los casos de Bankers Trust o Chemical Bank (1994), Barings Bank, Daiwa o Wisconsin Investment Borrad (1995), Sumitomo (1996), Natwest (1997), Long Term Capital Management (1998) o Allied Irish Bank (2002), entre otros. 
Evolución del proceso de regulación bancaria hasta

Basilea2: Origen, características y posibles efectos

\section{HACIA LA REGULACIÓN DE CAPITAL BANCARIO}

\subsection{El sector bancario en el sistema financiero}

En un mercado de competencia perfecta, los intermediarios financieros no cumplirían su actual función dado que los ahorradores (prestamistas) y gastadores (prestatarios) de títulos podrían asignar el riesgo eficientemente por sí solos (sin coste), los títulos serían infinitamente divisibles y los agentes conocerían la calidad real de lo que compran/venden. En este sentido, la existencia de las instituciones financieras se justifica por el incumplimiento de las condiciones del teorema de Modigliani y Miller.

Los bancos como parte del sistema financiero aportan ventajas en varios sentidos: disponen de información sobre las empresas y sus gestores, mejorando así la asignación de capital y el gobierno corporativo; gestionan los riesgos transversales, intertemporales y de liquidez, animando a la eficiencia inversora y al crecimiento económico, y movilizan el capital para explotar economías de escala (Levine 2002).

Las razones que sostienen la existencia de los intermediarios financieros y la abundancia de éstos en lugar de una única entidad, van desde la existencia de los costes de transacción hasta la asimetría de la información.

Según las primeras teorías de intermediación financiera, la principal tarea de los intermediarios era transformar títulos emitidos por las empresas en títulos demandados por los inversores (depósitos). Su papel destaca por la capacidad para dividir y transformar el riesgo, algo que los prestatarios no pueden lograr por sí solos bajo las mismas condiciones, debido a los excesivos costes de transacción. Por tanto, una de las principales funciones de los bancos es la reducción de los costes de transacción. Adicionalmente, permiten diversificar la cartera, manteniendo títulos distintos para dispersar la exposición al riesgo específico, tal y como sostiene la teoría de carteras.

Además, los intermediarios financieros contribuyen en gran medida a generar información, con el fin de solventar la asimetría que surge cuando prestamistas/prestatarios no están igualmente informados sobre las características que los títulos que venden/compran, a lo que se suma la ventaja a favor de los prestamistas. Esta asimetría puede tomar dos formas (Bhattacharya y Thakor 1993), según se produzca, respectivamente, ex-ante o ex-post: 
- Selección adversa: surge antes de consumar una transacción financiera, ya que la parte con menos información no puede distinguir la buena/mala calidad de lo ofrecido por la contraparte, suponiendo que la peor opción es la más probable, al ser la de más interés para el otro (Akerlof 1970).

- Moral hazard: se refiere a los incentivos que tienen depositantes y directivos para asumir un mayor riesgo con posterioridad a la transacción, involucrándose en actividades que incrementan la probabilidad de un mal desempeño (aprovechando, por ejemplo, la liquidez tras recibir un préstamo, para acometer proyectos más arriesgados).

Finalmente, las teorías más modernas ofrecen dos explicaciones mayoritarias a la existencia de intermediarios, valorándolos como proveedores de servicios de liquidez y de supervisión.

\subsection{La necesidad de una regulación bancaria}

Son numerosas las razones esgrimidas a favor de la intervención regulatoria, desde la idea de que ésta puede conducir a una mejora hacia el óptimo paretiano cuando el acceso desigual a la información obstruye los mecanismos del mercado (Santos 1999), pero puede afirmarse que dos son las explicaciones que predominan: una posible crisis sistémica y la necesidad de supervisar a los bancos.

a) El riesgo de una crisis sistémica

La provisión de los bancos de un servicio de liquidez les expone a grandes demandas, que pueden producirse sin la emisión de información adversa sobre las activos bancarios, e incluso cuando hay información perfecta sobre éstos.

En esta situación, si un banco falla y no es capaz de atender a los depositantes en tiempo y/o cantidad, debería ser disuelto lo antes posible para evitar una demanda masiva; cuanto más tiempo se permita actuar a un banco insolvente, más tiempo tendrán los depositantes para 
Evolución del proceso de regulación bancaria hasta Basilea2: Origen, características y posibles efectos

retirar sus fondos y, en consecuencia, despojar a los bancos de sus activos de valor ${ }^{3}$.

Kaufman (1996) argumenta que en la mayoría de economías, el fracaso de un banco a nivel individual no debería ser más importante que el de cualquier otra empresa de tamaño similar, más si cabe en el contexto actual de mayor oferta de productos y desintermediación financiera, en que los productos ofrecidos por los bancos son diversos y otras entidades no-bancarias ganan cuota de mercado a expensas de ellos. Lo que verdaderamente distingue a las quiebras bancarias es el temor a que ese fracaso se extienda a otras entidades e incluso más allá del sistema bancario hacia el sistema financiero en conjunto, a la economía nacional o incluso a un ámbito internacional. En definitiva, el riesgo que subyace es la aparición de una crisis sistémica favorecida por la interconexión entre los agentes económicos, que supone una cadena que transmite los shocks de un agente al resto.

Estas quiebras bancarias son costosas ${ }^{4}$ y suponen importantes externalidades para la economía, ya que el proceso de quiebra destruye recursos y puede contagiarse, disminuye la confianza en el sector bancario y genera inestabilidad financiera (Freixas y Saurina 2004).

Además de la inestabilidad macroeconómica, es posible identificar un conjunto de elementos comunes en las crisis bancarias (Llewellyn 2002: 154): supervisión inadecuada o con escasos incentivos (regulación de capital inexistente o no fomentada, indulgencia en los estándares de clasificación de préstamos, dudosa actuación ante problemas de solvencia...); inapropiada revelación de información; problemas en los acuerdos de gobierno corporativo de los bancos; peligrosas prácticas bancarias (entidades que operan con ratios de capital por debajo de los exigidos, excesivo y rápido crecimiento del préstamo, débiles sistemas de control y gestión de riesgos, no inclusión de la prima de riesgo adecuada

3 Además, entre las causas que motivan las crisis bancarias, Curie (2004) destaca la falta de confianza de inversores y depositantes debido al empeoramiento de la calidad de los activos, la mala gestión de los pasivos o las grandes diversificaciones.

4 Hoggarth et al. (2001) demuestran empíricamente que las pérdidas son superiores cuando a la crisis bancaria se une una crisis cambiara, produciéndose "crisis gemelas". Concluyen también que la duración es mayor en países desarrollados, en los que son las crisis bancarias las que afectan significativamente al output, mientras que en los países emergentes el mayor efecto lo provocan las crisis cambiarias. 
en los tipos de los préstamos, estándares de contabilidad y política de provisiones inadecuados...) y falta de disciplina de mercado.

En una situación de crisis, todas las entidades que compiten en el mercado perciben el aumento del riesgo e instintivamente tratan de protegerse contra él, actuando de forma similar (deshaciéndose de los activos de mayor riesgo y comprando instrumentos de cobertura). Este comportamiento de rebaño (herd behaviour) acentúa la crisis, dado que eleva la volatilidad, desestabiliza el mercado y aumenta la fragilidad del sistema financiero (Bikhchandani y Sharma 2001; Daníelsson 2002).

Ante esta posibilidad de que tenga lugar una crisis sistémica, son numerosas las propuestas relativas a la regulación bancaria: desde el papel del banco central como prestamista en última instancia, la creación de un seguro de depósitos, imposición de restricciones a la actividad ${ }^{5}$, requisitos de solvencia, exigencia de capital mínimo y, por último, supervisión bancaria.

Siendo las grandes demandas de liquidez una de las características principales de esa crisis bancaria general, y en línea con lo anterior, Santos (2000) recoge algunas propuestas para alejar a los bancos de estas grandes demandas, como la creación de bancos restringidos (que sólo puedan invertir en títulos sin riesgo), de fondos bancarios con acciones más que depósitos de demanda (lo que convierte a los bancos en inmunes a las grandes demandas), comprometerse a no liquidar más que una porción de los activos necesarios para satisfacer las demandas de liquidez de aquellos consumidores que desean consumirlos pronto y eliminando el incentivo a las grandes demandas de los demás, utilizar el banco central como prestamista en última instancia, o que el gobierno ofrezca un seguro de depósitos.

Uno de los mecanismos más significativos es el seguro de depósitos, que pretende contribuir a superar la asimetría de información que se produce en el sistema bancario (Diamond y Dybvig 1983), dado que

5 Se trata de las decisiones del regulador sobre las actividades que pueden desempeñar las entidades financieras. Varias razones sostienen que el regulador puede mejorar el funcionamiento bancario restringiendo su actividad: potenciales conflictos de interés que surgirían si los bancos se embarcaran en dichas actividades, asumir más riesgos debido a la existencia de moral hazard, la dificultad de supervisar a las entidades más complejas, el excesivo poder de esas entidades para someterse a la disciplina necesaria, sin olvidar los efectos sobre la competencia. Sin embargo, esta restricción podría traer también efectos negativos: más probabilidad de sufrir una crisis bancaria y reducción de la eficiencia del sector (Barth et al. 2004). 
los bancos tienen un conocimiento superior sobre el riesgo de sus operaciones al que tienen los depositantes. Se desarrolló por primera vez en Estados Unidos en 1934, al objeto de prevenir futuras demandas bancarias (como las acaecidas durante la Gran Depresión), y se extendió a otros países a partir de mediados de siglo, generalizándose en la mayoría de economías de la OCDE en los años ochenta.

La existencia de un seguro de depósitos refuerza la seguridad por parte de los depositantes de la recuperación de sus depósitos y reduce las posibilidades de que se produzca una demanda masiva de fondos. Así, se minimizan los incentivos de éstos para evaluar el nivel de riesgo de su inversión y, en consecuencia, exigir más rentabilidad, dado que en caso de insolvencia de la entidad depositaria, el reembolso está garantizado, hasta un determinado importe, por el seguro. Esto puede conducirles a depositar su dinero en entidades que asumen mayores riesgos a cambio de ofrecer altas rentabilidades (Young y Ashby 2001). En consecuencia, en ausencia de seguro de depósitos, y en base a la teoría de las expectativas racionales, los depositantes deberían exigir un tipo de interés para sus depósitos en función del nivel de riesgo que asume la entidad.

El sistema de seguro de depósitos más usual es la aportación de una prima fija (en función del tamaño de los depósitos, e independientemente de la situación financiera, nivel de capitalización y riesgos asumidos por la entidad), aunque esto pueda conducir a la aparición de moral hazard, de modo que se incrementa el riesgo del activo sin incrementar el capital mantenido; de este modo, el banco no internaliza el coste total del riesgo y tiene el incentivo de asumir más riesgos ${ }^{6}$.

b) Los depositantes no pueden vigilar a los bancos

Este argumento se fundamenta en la existencia de un problema de agencia, dado que el principal (los depositantes) no puede

6 Esta es una de las razones que puede justificar la necesidad de mecanismos de supervisión de solvencia, para así proteger al asegurador y controlar la actividad de las entidades, fijando un límite al apalancamiento y al riesgo asumido (García Higuera 2001; Dowd 1999). Otra posibilidad es ajustar las primas del seguro al riesgo, de modo que clasifiquen los instrumentos financieros asegurados en distintas categorías de riesgo con tasas diferentes. Estas clasificaciones dependerían de factores como la adecuación de capital, rentabilidad, concentración de activos y una puntuación otorgada a la entidad por el regulador (Gueyie y Lai 2003). El razonamiento es idéntico a la concesión de préstamos con intereses superiores a los clientes de mayor riesgo (Oatley 2001). 
vigilar al agente (banco), que está sujeto a los problemas de moral hazard y de selección adversa ya mencionados. Dicha supervisión es costosa y requiere, entre otras cosas, acceso a información. Además, duplicarla por varias partes es desaprovechar recursos. Por tanto, es necesario un representante de los depositantes: el regulador.

\subsection{Argumentos contra la regulación bancaria}

Según Kaufman (1996), el mayor peligro de riesgo sistémico surge, no del daño que puede infringir a la economía un conjunto de fallos bancarios, sino de los efectos adversos de políticas públicas adoptadas para prevenirlo. Como resultado, se puede argumentar que el pobre desarrollo de la banca experimentado en la mayoría de países en las últimas décadas refleja fallos gubernamentales o regulatorios más que fallos del mercado ${ }^{7}$.

En el caso de algunas industrias bancarias, la liberalización ha aumentado la competitividad dentro del sector, incentivando a las entidades a trabajar de forma más eficiente y/o asumir más riesgos (DeYoung et al. 2001). Por tanto, cabe pensar que la proliferación de quiebras bancarias en los últimos años del siglo XX se originó en gran parte por las regulaciones tendentes a garantizar la seguridad ante los pánicos bancarios, y que el modo de garantizar realmente la estabilidad financiera es permitir que el sector funcione con la mínima intervención reguladora.

2.4. El capital como instrumento de regulación bancaria: Hacia la regulación actual

Se entiende por capital bancario la diferencia entre el valor de mercado de los activos y depósitos (pasivos) bancarios, de modo que un banco entra en default económicamente cuando el valor de mercado de sus activos se sitúa por debajo del valor de mercado de sus pasivos,

7 En el mismo sentido, Honohan y Klingebiel (2000) explican que las medidas encaminadas a gestionar las crisis bancarias dan como resultando elevados costes fiscales, mientras que Flannery y Rangan (2002) concluyen, a partir del estudio del sistema bancario estadounidense, que la introducción del capital mínimo regulatorio no ha afectado al nivel de capital que mantienen las instituciones financieras. 
siendo el valor de mercado de su capital (riqueza neta) negativo (Kaufman 1992; 1996).

Admitiendo que los bancos precisan, en cierto grado, ser regulados por los supervisores, es conveniente justificar la traducción de estas exigencias en requisitos de capital. Así, considerando el capital como la diferencia entre activos y depósitos, cuanto mayor sea el ratio que relaciona capital y activos, mayor seguridad presentarán los depósitos ${ }^{8}$. La exigencia de requisitos de capital permite además alinear los incentivos de los propietarios del banco y los depositantes y otros acreedores, reduciendo así el problema de agencia.

Adicionalmente, el capital puede convertirse en un medio adecuado para instrumentar la regulación bancaria en relación a los dos principales argumentos que la sostienen.

En primer lugar, para el argumento del riesgo sistémico las reglas de adecuación de capital requieren a los bancos mantener un nivel mínimo de recursos propios, reduciendo la probabilidad de insolvencia y, en consecuencia, el riesgo para una entidad derivado del colapso de otras (Beattie et al. 1995: 34).

En segundo lugar, desde la perspectiva de la representatividad de los depositantes, una asignación eficiente de los derechos de control entre accionistas y gestores necesita tener en cuenta el hecho de que los depositantes no tienen capacidad para supervisar a los gestores, ya que son pequeños y están desinformados: necesitan un representante. Las exigencias de solvencia mínima deberían formar parte de una regulación efectiva si se define el umbral de transferencia de control al regulador (Dewatripont y Tirole 1993). actual ha pasado

Bajo estas premisas, el camino hacia la regulación bancaria de una regulación estructural, con normas que limitaban la capacidad de maniobra de las entidades respecto a los precios, las cantidades y la capacidad instalada, a una regulación prudencial, donde se otorga libertad operativa pero se vigila la valoración de los activos y la existencia

8 Así, a un determinado nivel, se considera que, por un lado, el capital es "adecuado" y, por otro, los depósitos son "seguros" (Sharpe 1978), existiendo un ratio de capital óptimo (Barrios y Blanco 2003) y definiéndose la adecuación de capital como expresión de solvencia. Por eso, el principal objetivo del capital en una institución financiera, más que la financiación de los activos, es la absorción del riesgo financiero (Matten 2000). 
de un nivel de recursos propios acorde al riesgo incurrido por las entidades (Saurina Salas 2002: 129).

El punto de inflexión en la regulación bancaria internacional puede situarse en la crisis de 1929, cuando se asume la importancia de que las instituciones bancarias tengan un respaldo financiero de sus dueños suficiente para afrontar dificultades temporales, convirtiéndose el capital en vehículo de control de la probabilidad de quiebra. El capital debe, por tanto, tener en cuenta que dicha probabilidad de quiebra se relaciona con los riesgos asumidos y que deben intentar minimizarse las distorsiones introducidas por la regulación, ya que así serán menores los cambios en el comportamiento. En este sentido, los efectos que pueden provocar las reglas de adecuación de capital son variados ${ }^{9}$, además de determinar la gestión de riesgos (Gallati 2003; Chorafas 2004b).

En cualquier caso, cabe preguntarse cuál es el nivel de capital que las entidades financieras deberían mantener. Así, mientras que los accionistas pretenderán minimizarlo, para lograr un mayor retorno sobre el capital, los acreedores y supervisores intentarán elevarlo, a fin de que haya un colchón mayor para protegerse contra las pérdidas y los problemas sistémicos.

9 Para un banco que pretende maximizar su valor, los incentivos para aumentar el riesgo de los activos disminuyen al aumentar el capital (Furlong y Keeley 1989). Sin embargo, Rime (2001) confirma que la presión regulatoria sobre el capital no altera el nivel de riesgo. Por el contrario, Kahane (1977), Koehn y Santomero (1980), Flannery (1989), Bhattacharya y Thakor (1993), Calem y Rob (1996), Kwan y Eisenbeis (1997), Blum (1999) y Oatley (2001) consideran que un incremento en el capital requerido puede conducir a una mayor asunción de riesgos bancarios. En concreto, Kahane (1977) se plantea la efectividad de restringir la composición de la cartera de activos y pasivos para así controlar la solvencia, precisando además de requisitos de capital, como corroboran Koehn y Santomero (1980), que consideran que la regulación debe afectar a la composición del activo y el capital. Kim y Santomero (1988) y Rochet (1992) muestran que las ponderaciones de riesgo elegidas inapropiadamente pueden aumentar el peligro para los bancos. Otros autores argumentan que los requerimientos de capital disminuyen los incentivos de supervisión, lo que reduce la calidad de las carteras bancarias (Besanko y Kanatas 1993; Boot y Greenbaum 1993). Blum (1999) introduce un nuevo efecto intertemporal que podría conducir a un aumento del riesgo, de modo que bajo requerimientos de capital obligatorios, la única posibilidad de aumentar el capital mañana es aumentar el riesgo actual. Además, los estándares de capital basados en riesgo adolecen ciertas deficiencias (Jones y Mingo 1999). Para Barth et al. (2004) la exigencia de los requisitos de capital es especialmente beneficiosa cuando existen generosos incentivos que distorsionan el seguro de depósitos, la supervisión oficial es débil y los bancos complejos son difíciles de supervisar. Dewatripont y Tirole (1995) analizan las reglas de capital como medios para asignar eficientemente derechos de control entre distintos grupos de claimholders (reclamadores), influyendo indirectamente sobre los incentivos de los gestores bancarios. Gehrig (1995) señala que los requerimientos de capital influyen en la naturaleza de la competencia estratégica entre los bancos, y Tsomocos (2003) que existe un trade-off entre los requisitos y la eficiencia bancaria. 
Evolución del proceso de regulación bancaria hasta

Basilea 2: Origen, características y posibles efectos

\title{
3. REGULACIÓN INTERNACIONAL BANCARIA: TRATAMIENTO
}

\section{DEL RIESGO}

\subsection{El Acuerdo de 1988}

\begin{abstract}
El Acuerdo de Capitales de Basilea ("Convergencia internacional de medidas y estándares de capital") surge como consecuencia de la preocupación creciente por la salud financiera de los bancos internacionales y las crecientes sospechas de competencia desleal, de modo que el Comité de Supervisión Bancaria de Basilea (en adelante, el Comité) comenzó a considerar propuestas para fijar estándares de capital en estos bancos ${ }^{10}$. El Acuerdo se firmó el 11 de julio de 1988, se hizo efectivo en marzo de 1989 y se requirió su introducción paulatina hasta diciembre de $1992^{11}$.
\end{abstract}

Este Acuerdo sólo considera explícitamente el riesgo de crédito. Exige a los bancos internacionales de los países del G-10 que mantengan un capital mínimo total equivalente al $8 \%$ de los activos ajustados al riesgo ${ }^{12}$, establecido a partir de los estados financieros consolidados de la entidad, con al menos la mitad de dicho capital en el "tier 1" (acciones ordinarias y reservas reveladas). El "tier 2" podría incluir, entre otros, instrumentos de capital de deuda híbrida.

Posteriormente, el Acuerdo ha sido renovado para tener en cuenta la innovación financiera y algunos de los riesgos no considerados inicialmente. En este sentido, en 1996 se introdujo una modificación para

10 Otras causas figuran también entre los motivos del Acuerdo. Así, en la década de los ochenta, varios bancos norteamericanos se vieron en peligro como consecuencia de la crisis latinoamericana. La parte del gasto que debió asumir EE.UU. motivó la exigencia de tensar la regulación bancaria y elevar el capital requerido, a lo que la industria bancaria respondió con alusiones a los efectos de esa política sobre la competencia, pidiendo un acuerdo internacional. Además, para la banca estadounidense y europea, los bancos japoneses estaban sub-capitalizados y extendían su ámbito de negocios rápidamente hacia otras regiones, beneficiándose de los altos beneficios que conseguían en su protegido mercado doméstico con bajos ratios de capital, algo que, a nivel internacional, podía suscitar problemas de competencia (Ito y Sasaki 2002).

11 Previamente, en 1986 el Banco de la Reserva Federal y el Banco de Inglaterra emitieron una propuesta de capital regulatorio denominada "Risk-based capital" (Capital basado en riesgo) que pretendía solventar las debilidades del capital primario que sostenía el sistema regulatorio norteamericano junto con el seguro de depósitos y el papel de la Reserva Federal desde los años 30.

12 Definidos como la suma de los activos ajustados al riesgo dentro y fuera de balance. Los activos en balance se asignaban a uno de los cuatro compartimentos $(0 \%, 20 \%, 50 \%$ ó $100 \%$ ) y se valoraban según esa ponderación. (Así, un activo con ponderación 100\% exigirá mantener capital por el $8 \%$ de su valor, mientras que con ponderación $20 \%$, tan sólo supondría capital del $1,6 \%$ de su valor). Los contratos contingentes fuera de balance debían ser previamente convertidos en un crédito equivalente y después multiplicados por la ponderación apropiada de riesgo. 
requerir a los bancos reservar capital con el objetivo de cubrir el riesgo de pérdidas procedentes de cambios en los precios de mercado. Este cambio definió un "tier 3" para cubrir riesgos de mercado y permitió a los bancos contar con deuda subordinada en esta banda. De este modo, el riesgo de mercado se convirtió en el primero en que las prácticas que se desarrollaban sobre gestión de riesgos se trasladaban al proceso regulatorio.

Esta enmienda recoge dos métodos para medir el riesgo de mercado: el método estándar y los modelos internos ${ }^{13}$. En relación al primero, el documento se refiere expresamente al riesgo de tipo de interés, riesgo de posición de equidad, riesgo de tipo de cambio, riesgo de materias primas y tratamiento de opciones. Por otro lado, la aplicación de un modelo interno requiere la aprobación del supervisor y el cumplimiento de una serie de requisitos cuantitativos y cualitativos.

\subsection{Impacto del Acuerdo y motivos de reforma}

En 1999 el Comité elaboró un documento de trabajo (BCBS 1999a) al objeto de analizar el comportamiento de los bancos después del Acuerdo de Basilea y antes de la próxima reforma del mismo, con un doble objetivo: evaluar si la adopción de requerimientos de capital mínimos fijos conducía a mantener ratios de capital superiores a los que habrían mantenido de otro modo y si un incremento en los ratios se había logrado aumentando el capital o reduciendo los activos bancarios, a fin de valorar el éxito al limitar el riesgo asumido.

El grupo de trabajo concluyó que la introducción de requerimientos de capital mínimos formales entre los países del G-10 parecía haber inducido de forma relativamente débil a las instituciones capitalizadas a mantener ratios de capital más altos. Así, el ratio medio de capital respecto a activos ajustados al riesgo de los grandes bancos del G-10 aumentó desde el 9,3\% en 1988 al 11,2\% en 1996, aunque es difícil

13 En el primer documento de consulta sobre la cobertura del riesgo de la cartera de negociación (BCBS 1993), el Comité sólo proponía el método estándar (siguiendo su línea habitual de establecer un patrón regulatorio uniforme) pero, ante las presiones de los bancos más avanzados, que habían desarrollado modelos valor-en-riesgo (VaR), el Comité aceptó los modelos internos como opción. 
Evolución del proceso de regulación bancaria hasta

Basilea 2: Origen, características y posibles efectos

discernir si esos aumentos reflejan los efectos directos del Acuerdo de Basilea $^{14}$.

Además de los elevados ratios de capital, otros hechos han sido achacados al Acuerdo. Es el caso de las dificultades crediticias de principios de los noventa, ya que los requisitos de capital más exigentes redujeron la tolerancia de los bancos al riesgo. Además de estos problemas crediticios, otros comportamientos del mercado bancario (herd behaviour, reacciones o cambios en las pólizas) son respuestas óptimas a shocks idiosincráticos o sistémicos (Pecchenino 1998).

A la vista de estos elementos, varias razones sostienen el proceso de revisión antes aludido:

- El modelo de 1998 era demasiado simplista y no fomentaba la coincidencia entre capital regulatorio (exigido por la regulación) y capital económico (necesario dada la situación real de riesgo). Teniendo en cuenta que la exigencia de capital influye en la toma de decisiones de inversión, la regulación puede distorsionar la asignación de recursos financieros.

- Se pretendían premiar los esfuerzos de los bancos para mejorar la gestión del riesgo. En efecto, una de las críticas más notables al Acuerdo era su falta de sensibilidad al riesgo, que puede llegar a distorsionar la toma de decisiones (Saidenberg y Schuermann 2003). Así, si el capital requerido no se basa en un estándar (como la probabilidad de insolvencia), los bancos reestructurarán sus carteras para disminuir el capital sin reducir el riesgo, optando por operaciones de más riesgo, ya que son las que conllevan márgenes superiores exigiendo el mismo capital, surgiendo arbitraje de capital regulatorio, reduciendo el capital requerido sin una reducción correlativa del riesgo asumido.

14 Los efectos del Acuerdo se han analizado en muchos países. En el caso de Japón, ha contribuido a generar tensiones financieras (Hall 1993), ha reducido la toma de riesgos (Konishi y Yasuda 2004), y ha modificado el comportamiento de los bancos con actividad internacional (Montgomery 2005). De hecho, una las intuiciones que derivan del Acuerdo de Basilea es que los bancos pretenden minimizar el capital y, debido a esto, es precisa una regulación que les obligue a soportar una cifra mínima, mientras que la evidencia empírica demuestra que los bancos están soportando más capital del exigido. Por tanto, cabe preguntarse a qué se debe esa sobrecapitalización. Una posible respuesta es que las fuerzas del mercado empujan a las entidades a tal decisión, y otra, que se produce un problema de asimetría de información, dado que los gestores del banco (a los que se supone un mayor conocimiento de su actividad) consideran que el nivel fijado por el regulador es insuficiente en relación a los riesgos tomados por la entidad, en contra de la opinión supervisora. 
- Se intentaban incluir en el Acuerdo otros elementos de la doctrina supervisora como la disciplina de mercado y algunos aspectos de las técnicas de control interno.

- Era necesario ampliar la lista de riesgos cubiertos con capital, en respuesta a la nueva problemática de las entidades financieras, como la relevancia del riesgo operacional. Era evidente, por tanto, que las condiciones de la actividad bancaria habían cambiado, convirtiendo al Acuerdo en obsoleto.

Con estas ideas de fondo, en junio de 1999 se publica el primer documento consultivo (CP1), en el que el Comité explicita los objetivos del nuevo Acuerdo: continuar fomentando la seguridad y viabilidad del sistema bancario (manteniendo al menos el nivel global de capital en el sistema, así como la igualdad competitiva), ampliar el enfoque de tratamiento de riesgos, y desarrollar esquemas de adecuación de capital sensibles al nivel de riesgo. Es decir, se pretende introducir el principio de discriminación de riesgos, exigiendo una gradación de capital para respaldarlos, más elevado cuanto mayor sea el riesgo que se asume. Se logrará así acercar el capital regulatorio y económico.

Además, la coexistencia de modelos estándar e internos implicaba un objetivo cuantitativo: que las entidades que adopten la metodología estándar no vean incrementados los requisitos de capital, y que si optan por las metodologías internas, el capital tienda a disminuir. La importancia otorgada al desarrollo de los modelos internos por parte de los bancos implica que el Comité asume que existen notables diferencias entre las entidades afectadas.

\subsection{El Nuevo Acuerdo de Capital Bancario: Basilea-II}

Los cinco años que enmarcan el proceso de elaboración de Basilea-2 derivan de las continuas propuestas del Comité, la toma en consideración de otras opiniones de los reguladores y supervisores, y las sugerencias de las entidades implicadas. De este modo, el CP1 fue seguido del CP2 (enero 2001) y CP3 (abril 2003) hasta la publicación definitiva del acuerdo el 26 de junio de 2004. En paralelo, el Comité creó el Grupo de Implementación del Acuerdo (Accord Implementation Group o AIG) en diciembre de 2001, con el objetivo de ayudar en la puesta en marcha de Basilea-2 de forma consistente entre los distintos países, sirviendo además de foro para la puesta en común de los supervisores. 
A continuación se resumen las principales características del Acuerdo, a fin de valorar sus posibles efectos, con especial hincapié en su vinculación con el ciclo económico.

\subsubsection{Estructura del Acuerdo}

La estructura de Basilea-2 se desarrolla a través de tres pilares, reconociendo que el capital no puede sustituir por sí solo una adecuada gestión y control de riesgos. Además, la inclusión de modelos internos con fines regulatorios incide en este nuevo enfoque, incorporando requisitos cualitativos (además de los cuantitativos) y la necesaria aprobación del supervisor. El primer pilar incide en la adopción de reglas uniformes, el segundo en una supervisión más personalizada y discrecional, y el tercero en el efecto disciplinario que supone la supervisión del mercado.

Se espera que la experiencia adquirida en la utilización de modelos internos para el riesgo de mercado ayude al caso de los riesgos de crédito y operacional, pese a que la complejidad en la modelización de este último sea muy superior, y la inevitable dependencia, en cualquiera de los casos, de una base de datos con información suficiente.

a) Pilar 1: Requisitos de capital mínimos

En el pilar 1 se definen los recursos propios mínimos, fijados en el $8 \%$ del capital en relación a los riesgos asumidos. La definición de capital no varía respecto al Acuerdo de 1988, añadiendo en el denominador el riesgo operacional. La revisión se centra en el riesgo de crédito y riesgo operacional, manteniéndose para el riesgo de mercado el tratamiento aprobado en el documento de 1996. La adecuación de capital se mide, por tanto, como sigue ${ }^{15}$ :

$$
\begin{gathered}
\frac{\text { Capital Total }}{\text { R.crédito }+12.5(\text { R.mercado }+ \text { R.operacional })} \geq \text { ratio capital banco (mínimo 8\%) } \\
\text { Capital Total } \geq 0.08 \text { R.crédito + R.mercado + R.operacional }
\end{gathered}
$$

15 La fórmula responde a las diferencias en el cálculo de los tres tipos de riesgo. Mientras que en el caso del riesgo de crédito se determinan directamente los activos ponderados, en los riesgos de mercado y operacional se calculan cifras de capital. Cabe comentar que CP1 apuntaba a la inclusión futura de otros riesgos a cubrir con capital en el pilar 1, como el riesgo de interés, pero CP2 decidió incorporarlo en el pilar 2. 
Tras la reunión de Madrid (octubre 2003) se especificó la calibración de los requerimientos de capital para protegerse sólo de las pérdidas no esperadas, de modo que las esperadas se cubrieran a través de provisiones. Ante el déficit de cobertura de las pérdidas esperadas, debe utilizarse el capital (a partes iguales entre tier 1 y 2 ), y en caso de exceso, éste puede considerarse, en todo o en parte, como tier 2.

Para el riesgo de crédito, el Comité ha considerado las siguientes aproximaciones para establecer los requerimientos mínimos de capital:

- El método estándar, que asigna una ponderación de riesgo a activos y operaciones fuera de balance para generar el total de activos ponderados por riesgo. Las ponderaciones dependen del tipo de prestatario (riesgo soberano, bancos o empresas) y desde ahora también de la calificación de una institución externa de evaluación de crédito (Cuadro 1).

- Los modelos internos (IRB - internal rating-based approach), en los que la entidad estima la calidad crediticia de cada prestatario y cantidad de pérdidas futuras potenciales ${ }^{16}$ a partir de cuatro variables: PD (probabilidad de incumplimiento), LGD (pérdida en caso de incumplimiento), EAD (exposición) y $M$ (vencimiento efectivo) ${ }^{17}$. Tiene dos variantes: en el método básico todas las magnitudes relevantes para la medición del riesgo de crédito están fijadas o al menos sujetas al supervisor, de modo que el banco sólo determina la PD, mientras que en el método avanzado los parámetros son determinados por el propio banco, aunque posteriormente se sometan al proceso supervisor.

16 Por tanto, en ambos esquemas es preciso recurrir a un sistema de ratings. Según Kirstein (2001), aunque los bancos cuentan con una capacidad de diagnóstico superior a las agencias de calificación, los ratings externos son más adecuados para logran los objetivos propuestos por el Acuerdo, ya que los bancos carecen de incentivos suficientes para revelar los resultados reales de su análisis.

17 El riesgo de crédito da lugar a la pérdida crediticia (importe no reembolsado por el prestatario y gastos asumidos para recuperarlo), aproximada a través de la pérdida esperada. No obstante, el verdadero concepto de riesgo se identifica con la pérdida inesperada o variación imprevista respecto a la esperada (estadísticamente, la desviación estándar). La pérdida esperada depende de dos parámetros: la frecuencia o probabilidad y la severidad o cuantía de la pérdida. Esta última se calcula como el cociente entre las pérdidas realmente asumidas (una vez considerada la parte recuperada) y la exposición a la pérdida o importe de la operación en el momento de la potencial entrada en mora del cliente. 
Cuadro 1. El Método Estándar para el Riesgo de Crédito

\begin{tabular}{|c|c|c|c|c|c|c|c|}
\hline & $\begin{array}{c}A A A a \\
A A-\end{array}$ & $\begin{array}{c}A+a \\
A-\end{array}$ & $\begin{array}{c}B B B+ \\
a B B B-\end{array}$ & $\begin{array}{c}B B+a \\
B B-\end{array}$ & $\begin{array}{c}B+a \\
B-\end{array}$ & $\begin{array}{c}\text { Por debajo } \\
\text { de } B-\end{array}$ & $\begin{array}{c}\text { No } \\
\text { clasificados }\end{array}$ \\
\hline Soberano(1) & $0 \%$ & $20 \%$ & $50 \%$ & $100 \%$ & $100 \%$ & $150 \%$ & $100 \%$ \\
\hline Calificación riesgo ECA (2) & 1 & 2 & 3 & 4 & 5 & 6 & 7 \\
\hline Ponderación del riesgo & $0 \%$ & $20 \%$ & $50 \%$ & $100 \%$ & $100 \%$ & $100 \%$ & $150 \%$ \\
\hline $\begin{array}{l}\text { Gobiernos regionales y } \\
\text { autoridades locales } \\
\text { Empresas públicas. Compañías } \\
\text { de valores }\end{array}$ & \multicolumn{7}{|c|}{ Mismo tratamiento que las entidades de crédito(3) } \\
\hline $\operatorname{Bancos}(4)$ & & & & & & & \\
\hline Opción 1 & $20 \%$ & $50 \%$ & $100 \%$ & $100 \%$ & $100 \%$ & $150 \%$ & $100 \%$ \\
\hline Opción 2 (5) & $20 \%$ & $50 \%$ & $50 \%$ & $50 \%$ & $50 \%$ & $150 \%$ & $50 \%$ \\
\hline Empresas & $20 \%$ & $50 \%$ & $100 \%$ & $100 \%$ & $150 \%$ & $150 \%$ & $100 \%(6)$ \\
\hline
\end{tabular}

(1) El término incluye gobiernos soberanos, bancos centrales y entidades del sector público tratadas como gobiernos soberanos por el supervisor nacional. Discrecionalidad nacional para otorgar un trato preferencial a los riesgos bancarios denominados y financiados en la moneda local del prestatario.

(2) Para ponderar los riesgos soberanos los supervisores pueden reconocer las calificaciones riesgo-país asignadas a los soberanos por las Agencias de Crédito a la Exportación (ECA, Export Credit Agencies), que deberán publicar sus calificaciones de riesgo y adoptar la metodología OCDE de 1999 para ser válidas. Los créditos frente al Banco de Pagos Internacionales, FMI, BCE y CE tendrán ponderación 0\%.

(3) Los estados tienen la discrecionalidad de asimilar el riesgo de sus propios gobiernos, autoridades locales y empresas públicas al del riesgo soberano.

(4) Discrecionalidad nacional para la elección entre ambas opciones (aplicarán sólo una de las dos opciones a todos los bancos de su jurisdicción). La opción 1 pondera una categoría menos favorable que la asignada para todos los créditos frente al soberano de incorporación (1), con un tope del $100 \%$ para créditos con bancos cuyos soberanos tengan una calificación de BB+ a B-.

(5) Los préstamos a corto plazo ( $\leq 3$ meses) ponderan en una categoría inferior, con un techo mínimo del $20 \%$. Este tratamiento no se aplica para bancos con ponderación de $150 \%$.

(6) Las empresas no calificadas no podrán recibir una ponderación inferior a la de su riesgo soberano.

Las posiciones con bancos y empresas que tengan evaluaciones de crédito externas más elevadas que las asignadas al soberano de incorporación, pueden recibir una ponderación de riesgo preferencial, pero nunca menor del $20 \%$.

Los créditos con bancos multilaterales de desarrollo (MDBs) se basarán en evaluaciones externas de crédito, aunque la ponderación será $0 \%$ en aquellos que reciban una calificación alta.

Para la medición del riesgo de mercado no se introducen novedades ${ }^{18}$ : para el caso del método estándar, se presenta el cuadro de vencimientos, y también es posible optar por el método basado en los modelos internos (VaR). Para Basilea, los riesgos de mercado que deben

18 Aunque sí se sustituye la definición de cartera de negociación, vigente desde 1996. Ahora ésta se compone de posiciones en instrumentos financieros y en productos básicos mantenidas con fines de negociación o al objeto de cubrir otros elementos de la cartera de negociación. Para ser admisibles en el tratamiento de capital regulador para la cartera de negociación, los instrumentos financieros deberán estar libres de toda cláusula restrictiva sobre su negociabilidad, o bien deberán poder recibir una cobertura total. Además, las posiciones deberán valorarse con frecuencia y precisión y la cartera deberá ser gestionada de forma activa (BCBS 2004b: par. 685). 
atenderse a requisitos de capital son los que corresponden a instrumentos y equities relacionados con tipos de interés en la cartera de explotación, y riesgos de tipo de cambio y commodities en toda la entidad.

Probablemente la mayor novedad de Basilea-2 sea la incorporación de una carga explícita para esos "otros" riesgos que previamente no se habían reconocido de forma independiente: riesgos operacionales. El Acuerdo de 1988 sobrevaloraba de forma voluntaria la carga de capital por riesgo de crédito para reconocer una cobertura para otras categorías. El crecimiento exponencial en el uso de la tecnología, el incremento de las inter-relaciones entre los participantes en el mercado financiero a nivel mundial, la complejidad en las operaciones y una creciente preocupación por el riesgo, los nuevos desarrollos de la industria financiera, la desregulación, la globalización, fusiones y adquisiciones a gran escala, outsourcing, tecnologías automatizadas, e-banking, etc., son algunas de las características actuales que rodean el sistema bancario y explican la importancia de estos riesgos. Si nos atenemos a la definición causal ofrecida por el $\mathrm{BCBS}$, se tratará del riesgo de pérdida directa debido a la inadecuación o a fallos en los procesos, el personal y los sistemas internos o bien a causa de acontecimientos externos, incluyendo el riesgo legal, pero no el riesgo estratégico y el de reputación.

Se proponen tres modelos de complejidad creciente que generarán el capital esperado (Cuadro 2). Se entiende que, a mayor volumen de negocio, mayor probabilidad de incurrir en riesgo operacional. Para todos ellos, excepto para el primero cuando no se prevea su mejora, la idea de fondo es que el riesgo operacional se gestiona mejor cuando se asocia a un indicador de riesgo con una relación causa-efecto (Chorafas 2004a). Dentro de los modelos más sofisticados, el Comité permite el desarrollo de modelos internos sin especificarlos ${ }^{19}$, aunque sujetos a ciertos requisitos. Sin embargo, en el documento de apoyo sobre riesgo operacional (BCBS 2001b) se hace referencia expresa a los que figuran en el Cuadro 2.

19 Ya en el CP3 el BCBS explica que "dada la continua evolución de los métodos analíticos de tratamiento del riesgo operativo, el Comité no desea especificar qué método o qué supuestos sobre distribuciones de probabilidad se deben utilizar para estimar el riesgo operativo a efectos de capital regulador" (BCBS 2003a: par.627). En el acuerdo definitivo, se repite esta idea (BCBS 2004b: par. 667). 
Cuadro 2. Modelos para el Cálculo de Capital por Riesgo Operacional

\begin{tabular}{|c|c|c|c|c|c|c|c|}
\hline & & & Método del Ind & licador Básico & & & \\
\hline$C_{o}=\sum\left(E I_{1 \ldots n} \cdot \alpha\right)$ & & & $\begin{array}{r}E I=\text { Inc } \\
\text { ing } \\
\alpha=15\end{array}$ & $\begin{array}{l}\text { dicador de exp } \\
\text { gresos brutos } \mathrm{p} \\
\%\end{array}$ & $\begin{array}{l}\text { osición (n } \\
\text { ositivos) }\end{array}$ & edia de tres ai & ños de los \\
\hline & & & Método $\mathrm{E}$ & stándar & & & \\
\hline$C_{0}=\left\{\sum_{a \tilde{n} o s 1-3} \max [\right.$ & $\sum\left(G I_{1-\zeta}\right.$ & $\left.{ }_{8} \cdot \beta_{1-8}\right),($ & $0]\} / 3$ Línea de & negocios $\Rightarrow$ & & & \\
\hline & & & Finanza & s corporal. $\rightarrow 1$ & $8 \%$ & sos y liquidac & $\rightarrow 18 \%$ \\
\hline & & & Negocia & c.y ventas $\rightarrow 1$ & $8 \%$ & v.agencia-cus & stodia $\rightarrow 15 \%$ \\
\hline & & & Banca $m$ & inorista $\rightarrow 12 \%$ & G & stión de activ & $\mathrm{os} \rightarrow 12 \%$ \\
\hline & & & Banca ce & omercial $\rightarrow 15^{\circ}$ & & ermed.minori & ista $\rightarrow 12 \%$ \\
\hline & & & étodos de Med & ición Avanza & & & \\
\hline & & & Método de M & edición Intern & & & \\
\hline $\begin{array}{c}\text { Tipo de evento } \Rightarrow \\
\text { Líneas de negocio } \\
\Downarrow\end{array}$ & \begin{tabular}{|l|} 
Fraude \\
Interno
\end{tabular} & $\begin{array}{l}\text { Fraude } \\
\text { externo }\end{array}$ & $\begin{array}{l}\text { Relaciones } \\
\text { laborales y } \\
\text { seguridad en } \\
\text { puesto trabajo }\end{array}$ & \begin{tabular}{|l|} 
Prácticas \\
con clientes, \\
productos y \\
negocios
\end{tabular} & $\begin{array}{l}\text { Daños a } \\
\text { activos } \\
\text { materiale }\end{array}$ & $\begin{array}{l}\text { Incidencias } \\
\text { en negocio } \\
\text { y fallos } \\
\text { sistemas }\end{array}$ & \begin{tabular}{|l|} 
Ejecución, \\
entrega y \\
gestión \\
procesos
\end{tabular} \\
\hline \begin{tabular}{|l|}
$\begin{array}{l}\text { Finanzas } \\
\text { corporativas }\end{array}$ \\
\end{tabular} & & & & & & & \\
\hline $\begin{array}{l}\text { Negociación } \\
\text { y ventas }\end{array}$ & & & & & & & \\
\hline Banca minorista & & & $\downarrow$ & & & & \\
\hline Banca comercial & & $\rightarrow$ & $E I_{43} P E_{43} L G E_{43}$ & & & & \\
\hline \begin{tabular}{|l|} 
Liquidación \\
y pagos
\end{tabular} & & & & & & & \\
\hline $\begin{array}{l}\text { Servicios } \\
\text { de agencia }\end{array}$ & & & & & & & \\
\hline $\begin{array}{l}\text { Administración } \\
\text { de activos }\end{array}$ & & & & & & & \\
\hline $\begin{array}{l}\text { Intermediación } \\
\text { minorista }\end{array}$ & & & & & & & \\
\hline
\end{tabular}

Para cada línea de negocios, la carga de capital es: $C_{0}=\sum_{i=1}^{n} \sum_{j=1}^{m}\left(\gamma_{i j} * E I_{i j} * P E_{i j} * L G E_{i j} * R P I_{i j}\right)$

siendo $P E$ la probabilidad, $L G E$ la cuantía, $\gamma$ determinado por el supervisor y $R P I$ el ratio pérdidas inesperadas/pérdidas esperadas.

\section{b) Enfoque de Distribución de pérdidas}

Es una aplicación de modelos actuariales que estima la distribución de pérdidas operacionales para cada combinación línea/tipo de evento, basada en determinados supuestos de frecuencia y severidad de los eventos. Las distribuciones más empleadas para la severidad son lognormal, valor extremo generalizado, Pareto generalizado o Weibull, y para la frecuencia la de Poisson. A diferencia del anterior, aquí se estiman las pérdidas inesperadas directamente, sin ninguna hipótesis sobre el ratio entre pérdidas esperadas e inesperadas.

El capital total requerido es la suma del VaR para cada línea de negocio/tipo de evento. Dado que las provisiones deberían cubrir las pérdidas esperadas, el capital debería centrarse en las pérdidas inesperadas ( $\mathrm{VaR}$ - pérdidas esperadas). 


\section{c) Aproximación por Scorecards}

El Comité hizo alusión a este enfoque en sus documentos de 2001 "Working paper on the regulatory treatment of operational risk" y "Sound practices for the management and supervision of operational risk", pero no en el documento final de 2004, por lo que puede considerarse como "best practice". En este enfoque la entidad calcula un capital inicial por riesgo operacional a nivel de entidad o línea de negocio, para modificarlo posteriormente en función de unos scorecards que intentan capturar el perfil de riesgo subyacente, el entorno de control existente y las variaciones que pudieran producirse en otros aspectos, exigiendo una fuerte base cuantitativa y precisando de la validación a través de datos históricos.

b) Pilar 2: Revisión supervisora de la adecuación de capital

Incorporar este pilar supone reconocer la existencia de otros elementos de riesgo, o matizadores del riesgo, además de los cubiertos con el capital mínimo del pilar 1 , de modo que las características de la política y gestión de cada entidad pueden sugerir la existencia de un mayor nivel de riesgo en su caso particular. Es por ello que los supervisores deben garantizar que los bancos cuenten con procesos internos adecuados para calcular la adecuación de capital mediante una evaluación exhaustiva de riesgos. A su vez, deben evaluar cómo calculan los bancos sus necesidades de capital en relación a éstos.

El objetivo de los supervisores al revisar la posición de capital del banco es asegurar que ésta es consistente con su perfil y estrategia media de riesgo y facilitar una pronta intervención supervisora si el capital no provee un tope suficiente contra el riesgo. Este proceso descansa en los siguientes principios (BCBS 2004b):

- Los bancos deberán contar con un proceso para evaluar la suficiencia de su capital total en función de su perfil de riesgo y con una estrategia para el mantenimiento de sus niveles de capital.

- Las autoridades supervisoras deberán examinar y evaluar las estrategias y evaluaciones internas de la suficiencia de capital de los bancos, así como la capacidad de éstos para vigilar y garantizar su cumplimiento de los coeficientes de capital regulador; deberán intervenir cuando no queden satisfechas con el resultado de este proceso.

- Los supervisores deberán esperar que los bancos operen por encima de los coeficientes mínimos de capital regulador.

- Los supervisores tratarán de intervenir con prontitud a fin de evitar que el capital descienda por debajo de los niveles mínimos requeridos 
para cubrir las características de riesgo de un banco dado. Asimismo, deberán exigir la inmediata adopción de medidas correctoras si el capital no se mantiene en el nivel requerido o no se recupera ese nivel.

El interés por este pilar ha ido en aumento a medida que las principales cuestiones sobre recursos propios se iban resolviendo ${ }^{20}$. Además, a través de este pilar se espera que las entidades tengan en cuenta el riesgo de tipo de interés de la cartera de inversión, liquidez, y otros (reputación y estratégico), además de los recogidos expresamente en el pilar 1.

\section{c) Pilar 3: Disciplina de mercado}

Anteriormente, la disciplina de mercado no se considerada entre las herramientas del supervisor bancario, entre otras razones, porque la regulación y la supervisión bancaria vienen a suplir una manifiesta deficiencia del mercado de depósitos bancarios para valorar a los bancos y seleccionar entre ellos, y porque en ese mercado se trata de evitar que funcione una pieza esencial de la disciplina de mercado (la quiebra de los ineficientes), por sus inaceptables repercusiones sociales y económicas.

Sin embargo, en los últimos años los organismos financieros internacionales y los foros de discusión sobre regulación bancaria abogan por una creciente transparencia de las entidades crediticias, y el Comité lo ha incorporado a sus trabajos, incluyéndolo como tercer pilar de Basilea-2. En efecto, el Comité advierte que un banco que se percibe seguro y bien gestionado puede obtener términos y condiciones comparativamente más favorables en sus relaciones con los inversores, acreedores, depositantes y otras contrapartes (BCBS 1998).

20 Las entidades han mostrado su preocupación por dos aspectos relacionados con este pilar (Iglesias-Sarria y Vargas 2004): en primer lugar, que suponga exigencias de capital adicionales automáticamente, ya que reconoce que los bancos se enfrentan a otros riesgos no incluidos en el pilar $1 \mathrm{y}$, sin considerarlos, los bancos pueden estar operando con niveles de capital inferiores a los necesarios. Es decir, los requisitos del pilar 1 responden al modelo supervisor y son mínimos, de modo que, si es preciso dar un paso más, se hará a través del pilar 2 . En segundo lugar, que su aplicación desigual entre los países desnivele el terreno de juego competitivo, debido a la notable discreción del supervisor (Méndez del Río 2003). 
Una disciplina de mercado efectiva requiere información relevante y oportuna que permita a las contrapartes realizar valoraciones de riesgo bien fundadas. Los bancos deberían publicar y revelar todas las cifras claves del capital mantenido como un colchón contra pérdidas, y las exposiciones al riesgo que pueden motivar tales pérdidas. La divulgación de información será semestral con carácter general, anual para aspectos cualitativos, y trimestral respecto al coeficiente de suficiencia de capital en el caso de bancos internacionalmente activos y otros bancos significativos. En la práctica, esto se convierte en un aumento de la información a rendir y la homogeneización de los estándares informativos, sin entrar en conflicto con los requisitos de la información contable.

No obstante, este proceso encaminado hacia la disponibilidad de información sobre riesgos bancarios en el mercado no puede valorarse de forma aislada, ya que requiere de una armonización contable a nivel internacional y unos estándares de revelación que impidan diferencias comparativas. Además, es previsible que los bancos se muestren reticentes a facilitar información que podría ir en beneficio de sus competidores.

El mayor impulso a este pilar se desarrolló en el CP2, distinguiendo entre requerimientos y recomendaciones e información básica y adicional. CP3 responde a las peticiones de la industria reduciendo los requisitos de información exigida pero confirmando su carácter obligatorio. Su redacción final implica indudables virtudes, enmarcadas en la mayor transparencia informativa, pero también costes asociados muy considerables.

\subsubsection{Valoración y posibles efectos de Basilea-II}

Durante el proceso de elaboración de Basilea-2, el Comité recibió numerosas propuestas y críticas, procedentes de reguladores nacionales $\mathrm{y} / \mathrm{o}$ regionales, entidades financieras y grupos de interés, que cuestionaban desde los modelos estadísticos propugnados por el Acuerdo hasta el análisis económico-financiero de las implicaciones que tendría su puesta en práctica. Entre los aspectos valorados pueden destacarse ${ }^{21}$ :

21 Una recopilación de estos planteamientos se puede consultar en "The New Basel Capital Accord: Comments received on the Second Consultative Package", en la url www.bis.org/bcbs/cacomments.htm. Véase también Jones (2000), Cantor (2001), Griep y De Stefano (2001), Altman et al. (2002), Sironi y Zazzara (2003), Rochet (2003) y Decamps et al. (2004). 
- No se reconoce la posibilidad de que los agentes reaccionen y alteren su comportamiento ante la regulación basada en el riesgo. Además, permite que la innovación financiera eleve los ratios de capital de los que las entidades informan sin que se presenten mejoras en la solvencia.

- Se aceptan determinadas hipótesis como certezas: por ejemplo, la propuesta reconoce explícitamente que Basilea- 2 tiene un impacto positivo en el comportamiento bancario y se confía en exceso en la habilidad de los modelos estadísticos para medir apropiadamente el riesgo.

- El cálculo del capital bancario a partir de una única medida del riesgo agregada, ya que la idea subyacente es que el riesgo de cada operación en una entidad financiera, sin importar su tamaño, se mide, agrega e incluye en el cálculo medio de riesgo del banco, surgiendo pues, un riesgo de modelo.

- Pese a la incorporación de nuevos esquemas regulatorios, existe un desequilibrio entre los tres pilares del Acuerdo, a favor del primero; la mayoría de los análisis formales sobre regulación de capital descansan en modelos estáticos, en los que los requisitos de capital se usan para limitar los incentivos de los bancos a una excesiva toma de riesgos. Además, el primer y tercer pilar son parcialmente sustituibles, igual que los pilares segundo y tercero.

- Respecto al tratamiento del riesgo de crédito, la propuesta del Comité sobre el modelo estándar desde el CP2 sobreestima el riesgo relativo de la deuda de alta-calidad respecto a la de baja, suponiendo así un incentivo a la toma de riesgos. Además, los estudios al respecto prevén posibles penalizaciones sobre la financiación interbancaria, o incrementos en la ponderación de riesgos.

- Las principales agencias de calificación aprueban la propuesta pero alertan sobre los posibles efectos en detrimento de la independencia de las agencias.

- En relación al riesgo operacional, algunos eventos antes asociados al riesgo de crédito y mercado pasan ahora a considerarse riesgo operacional, con las consiguientes implicaciones sobre el Pilar 1. 
- La elección de los ingresos brutos (gross income) como indicador de la exposición al riesgo operacional en el método del indicador básico y el método estándar suscita controversia. Esta variable no está relacionada con el riesgo operativo, ya que una entidad que logre mayores ingresos y al tiempo mejore sus procesos internos o sus métodos de gestión, en principio, reduciría su exposición a estas incertidumbres y, sin embargo, verá aumentar su carga de capital. Esto hace que los dos modelos de mayor simplicidad no sean sensibles al riesgo. Además, de existir una relación entre este indicador y el riesgo, no tiene por qué ser lineal, de modo que los supuestos del método son extremadamente restrictivos y difícilmente responden a la realidad. Asumir que existe esa relación lineal supone que las entidades con un negocio muy diversificado (menor riesgo) son tratadas comparativamente peor que las que se concentran en una única actividad. Podría también cuestionarse la inclusión de tres enfoques, dos de ellos de notable simplicidad, cuando la cobertura de opciones para todo tipo de bancos (más y menos sofisticados) se habría logrado con sólo dos de las propuestas, renunciando a uno de los modelos simples.

Una vez aprobado el Acuerdo definitivo, es recomendable valorar adecuadamente sus ventajas e inconvenientes. Entre las primeras, su carácter evolutivo y abierto, teniendo siempre en cuenta los continuos avances producidos en la industria. Sin embargo, ese carácter dinámico implica no sólo instalar los sistemas de modelización sino también afrontar los costes de su mantenimiento. Tampoco podemos olvidar que, pese a que el objetivo inicial de Basilea-1 era igualar el terreno competitivo de las entidades, Basilea-2 deja mayor margen a una aplicación desigual del Acuerdo, dado que presenta más elementos de discreción nacional y un contenido cualitativo superior. Además, entre los previsibles efectos de su puesta en práctica, cabe señalar:

- La posible aparición de una crisis crediticia, como ocurrió con su precedente ${ }^{22}$.

22 Sin embargo, los trabajos de Hancock et al. (1995) y Furfine (2001) simulan los efectos de Basilea-2 llegando a la conclusión de que su aplicación no conducirá a una crisis crediticia. 
- Implicaciones sobre la gestión estratégica de las entidades financieras, dado que el cambio en las necesidades de capital regulatorio puede incidir sobre el pricing, el ROE y el atractivo relativo de los negocios, y sobre la competencia. El comportamiento de las entidades puede verse afectado, ya que el mero hecho que fomentar la transparencia bancaria (pilar 3) a través del suministro de más información sobre riesgos, incidirá en otras decisiones.

- Se teme también que Basilea-2 afecte negativamente a las posibilidades de crecimiento de los países emergentes, al suponer una posible restricción o el encarecimiento de la financiación concedida, perjudicando así a los grupos internacionales cuya diversificación ha supuesto su expansión hacia estas zonas ${ }^{23}$. En el caso de América Latina, la Federación Latinoamericana de Bancos (Felaban) ha manifestado sus principales preocupaciones ante el Acuerdo en la conferencia "Efectos de la implementación de Basilea II en los mercados emergentes" celebrada en la ciudad de Panamá el 13 de abril de 2004: i) es preciso disponer de tiempo suficiente para aplicar el Acuerdo, que en el caso del continente sudamericano supone la adaptación y no tanto adopción de las recomendaciones de Basilea, ii) la estabilidad del sistema financiero puede verse perjudicada por el incremento de la volatilidad tras la adopción del Acuerdo en las economías más desarrolladas y la disminución de los plazos de los flujos de capital internacional, iii) el sistema financiero deberá emprender un proceso de modernización de la supervisión bancaria, y iv) se debe avanzar en el proceso de consolidación financiera y fusiones bancarias.

Entre las propuestas para mejorar las deficiencias del Acuerdo, figura la inclusión de requerimientos de deuda subordinada, uno de los mecanismos de mercado más efectivos para informar sobre el perfil de riesgos del banco, alineando los intereses de los poseedores de dicha deuda con los del depósito de seguros. Utilizar la deuda subordinada

23 No debe olvidarse que el impacto negativo de los requisitos de capital es superior en países en las condiciones que derivan de una crisis financiera, pudiendo incrementar las restricciones de liquidez (Chiuri et al. 2002). El estudio de Barajas et al. (2005) demuestra que tanto la capitalización bancaria como la actividad prestamista aumentó en América Latina después de Basilea-1, por lo que no hay por qué prever que el nuevo Acuerdo implique un descenso medio del crédito. Sí deben considerarse los efectos procíclicos, como se analizará a continuación. 
como mecanismo de mercado permite disminuir las pérdidas del fondo de seguro de depósitos en caso de quiebra, ya que los tenedores de esta deuda se ven expuestos al riesgo a la baja pero no se benefician del riesgo al alza, viéndose incentivados para vigilar el riesgo asumido por la entidad, imponiendo la disciplina de mercado ${ }^{24}$.

Respecto a los previsibles retos derivados de su puesta en práctica destaca, además del Pilar 2, la aplicación transfronteriza de los métodos avanzados de medición de riesgos, ya que un grupo internacionalmente activo que opte por estas metodologías puede tener que hacer frente a cargas adicionales si la aplicación de los distintos supervisores no es homogénea. Para solventar este problema, el Comité publicó un conjunto de principios elaborados por el AIG (BCBS 2003b; 2004a).

Pese a estas dificultades, se trata de un Acuerdo flexible y que puede responder a múltiples realidades. Así, su aplicación no es obligatoria salvo que así lo decidan los supervisores nacionales $\mathrm{y} / \mathrm{o}$ regionales. El Comité, consciente de ello, anticipa que los supervisores pueden preferir diferir la implementación de Basilea-2, ya que "necesitarán encontrar el equilibro adecuado entre la implantación de Basilea-2 y otras prioridades [...] porque los objetivos de Basilea-2 son promover la gestión de riesgos, adecuación de capital, disciplina de mercado y estabilidad financiera" (BCBS 2004c). En el otro extremo, el AIG también anima a los supervisores a poder ofrecer a los bancos internacionales más complejos y significativos la posibilidad de encaminarse hacia las metodologías más avanzadas.

\subsection{3. ¿Es Basilea-2 un Acuerdo procíclico?}

La interrelación entre el sector financiero y la economía real es notable, ya que ciertas variables financieras están positivamente relacionadas con la evolución económica, pudiendo afirmar pues, que existe cierta prociclicidad en el sector financiero, como demuestra empíricamente el comportamiento de las tasas de default (Koopman et al. 2005). Una vez más, una de las explicaciones subyacentes de esa prociclicidad está en la asimetría entre prestamistas y prestatarios ya

24 A este respecto, puede consultarse Evanoff y Wall (2000); Rodríguez (2003); Herring (2004); Freixas y Saurina (2004). 
comentada en la sección 2. En el caso del riesgo, las épocas de expansión vienen acompañadas por una actitud optimista (disminuye la percepción del mismo), aumentando así la exposición. Por el contrario, al concretarse algunos de esos riesgos en la fase recesiva, se reduce la exposición. Por tanto, el nivel del riesgo está correlacionado con determinados hechos sistémicos, como el ciclo económico, y varía cuando éste lo hace. Si convenimos que los sistemas financieros ya son procíclicos, la volatilidad excesiva tiene origen en el propio sistema financiero y no es un subproducto de la regulación.

La literatura también ha estudiado los efectos procíclicos de los requisitos de capital, pretendiendo avanzar hacia los capitales sensibles al riesgo. Así, Ayuso et al. (2004) demuestran que existe una relación negativa y significativa entre el ciclo económico y el capital mantenido, a partir de Basilea-1. Sin embargo, el efecto de este Acuerdo sobre el ciclo económico es discreto, ya que los beneficios han sido el primer colchón ante la necesidad de aumentar provisiones ${ }^{25}$ o dar de baja los préstamos, limitando así el impacto de las recesiones y la probabilidad de dificultades crediticias ("credit crunch").

En estos términos, la prociclicidad supone que los capitales requeridos sensibles a la situación económica pueden elevar el capital requerido en las fases bajistas, llevando a los bancos a restringir el suministro de crédito y fomentando así el ciclo económico. Si el nivel de capital requerido aumenta durante una recesión económica, un banco puede decidir reducir sus activos si éstos son insuficientes o incapaces de aumentar el capital hasta el nivel exigido. De este modo, varios niveles de cargas de capital pueden influir sobre el préstamo bancario, reforzando el ciclo económico. La prociclicidad del capital regulatorio podría originar graves desequilibrios macroeconómicos, acentuando la recesión si se generan dificultades crediticias. Del mismo modo, incentivarían el préstamo en las épocas favorables ${ }^{26}$.

25 Como se ha demostrado empíricamente, las provisiones son claramente procíclicas (Bikker y Metzemakers 2005). No aumentan hasta que el crecimiento económico no se ha reducido considerablemente y la economía entra en recesión. Así, son mayores cuando el crecimiento del PIB es inferior, reflejando el creciente riesgo de la cartera de crédito cuando el ciclo cae, lo que eleva el riesgo de credit crunch. Este efecto se mitiga dado que las provisiones aumentan cuando los beneficios y el crecimiento de los préstamos se eleva.

26 En ausencia de regulación, los bancos elegirían un esquema contracíclico, reduciendo los ratings durante la recesión. De este modo, si los reguladores prevén esto, los bancos optarán por un comportamiento procíclico (Catarineu-Rabell et al. 2003). Sin embargo, Borio et al. 
El crédito reviste especiales características procíclicas ${ }^{27}$. Dado que la estimación del riesgo aumenta durante las recesiones, los requisitos de capital en un sistema sensible al riesgo se elevarán. Si esto ocurre, y dada la dificultad y/o coste de generar reservas o capital adicional, los bancos se verán obligados a restringir el crédito, acentuando así la recesión y generando un círculo vicioso que podría finalmente afectar a la estabilidad del sistema bancario. De este modo, los requisitos de capital aumentan (disminuyen) durante una recesión (fase expansiva). En definitiva, todo sistema con requisitos de capital mínimos puede generar efectos procíclicos, ya que el capital disponible para afrontar dichos requisitos es más escaso en las recesiones, cuando el banco debe dotar provisiones y deshacerse de los préstamos fallidos.

$\mathrm{Si}$ los modelos de riesgo de crédito sobrevaloran (infravaloran) el riesgo de default en las malas (buenas) épocas, los requisitos de capital interno se fijarán muy elevados (bajos), forzando a los bancos que se ven apurados por el capital a retener el préstamo durante las recesiones y expandirlo en las fases alcistas, y dado que la mayoría de bancos están sujetos a las mismas fluctuaciones cíclicas, el efecto medio macroeconómico de las regulaciones de capital será acentuar el ciclo económico, empeorando así las recesiones. Por tanto, los requisitos de capital ajustados al riesgo son procíclicos.

Suele hacerse referencia a la tendencia de los bancos a contrarrestar por sí solos estos efectos procíclicos manteniendo colchones de capital durante las épocas expansivas. Sin embargo, la fase expansiva puede también caracterizarse por un mayor riesgo de crédito si surge asociada a un rápido crecimiento del crédito, importantes incrementos en los precios de los activos y altos niveles de inversión, ya que este tipo de sucesos son síntoma de la aparición de desequilibrios financieros (Lowe 2002). Las regulaciones propuestas inducirían en este caso a la armonización de las decisiones de inversión (herd behaviour) durante una hipotética crisis, con la consiguiente desestabilización del sistema financiero.

(2001) opinan que, desde el momento en que la prociclicidad deriva de una respuesta inadecuada de los participantes en el sistema financiero ante los cambios en el riesgo a lo largo del tiempo, surge la oportunidad de una respuesta regulatoria.

27 Dos son las causas que sostienen esta especial prociclicidad: i) el protagonismo y las características de la medición del riesgo en las decisiones propias de la actividad bancaria, ii) las respuestas de los agentes a las variaciones en la percepción del riesgo. Las épocas de sólido crecimiento económico suelen venir acompañadas de aumentos significativos en el ratio crédito /PIB, que desciende en las recesiones. De igual modo, el fuerte crecimiento del crédito va acompañado de incrementos en el precio de los títulos (González Mota 2005). 
Basilea-2 no parece escapar a dicha prociclicidad, dada la mayor sensibilidad del capital al riesgo que implica. Desde esta perspectiva, incidirá sobre la prociclicidad financiera si induce a un comportamiento del crédito bancario más volátil en relación a la evolución de la economía. Los factores de riesgos sistémicos pueden afectar tanto a la probabilidad como a la severidad, variables determinantes de pérdidas esperadas e inesperadas (Daníelsson et al. 2001; Allen \& Saunders 2004).

El principal análisis de Basilea-2 se refiere al riesgo crediticio, aunque la prociclicidad también está presente en los otros riesgos bancarios $^{28}$. De las tres variables determinantes en este caso (probabilidad, pérdida y exposición), puede inferirse un componente de riesgo sistémico en la exposición. En este sentido, es preciso evaluar los dos enfoques propuestos $^{29}$ : el método estándar (por el deterioro de los rating durante las recesiones) y el interno. Por tanto, son especialmente significativos dos aspectos relativos a este tema: el uso de calificaciones de rating y el desarrollo de modelos internos.

En Basilea-2 los requisitos de capital dependen de las evaluaciones crediticias de los prestatarios. Si esa evaluación empeora durante la fase recesiva, el capital a mantener aumentará. Por tanto, el efecto del capital requerido sobre la volatilidad dependerá de la calidad crediticia de la cartera de préstamos del banco.

28 En el caso del riesgo operacional, los factores sistémicos pueden afectar tanto a la probabilidad como a la cuantía (Allen y Bali 2004). Para el riesgo de mercado, admitiendo que viene determinado por la exposición de la cartera y la volatilidad del mercado, dada una exposición determinada, el riesgo de mercado aumentará si crece la volatilidad, y si los mercados están correlacionados también lo estará la volatilidad, derivando en cambios en la exposición. De este modo, si el nivel de capital de un banco depende del riesgo de mercado, aumentará en los períodos volátiles que tienen lugar en las crisis financieras, incidiendo en los vaivenes del mercado y suponiendo efectos procíclicos. Por tanto, los requisitos de capital basados en VaR serán procíclicos (Estrella 2004).

29 Véase Illing y Paulin (2004), Allen y Saunders (2004). Según Zakrajsek et al. (2001) la ciclicidad de la carga de capital sería menor aplicando el nuevo enfoque estándar en comparación con el Acuerdo de 1988. Según Kashyap y Stein (2004), Basilea-2 es procíclico en el caso del riesgo crediticio por trabajar con una única curva de riesgo, que relaciona la carga de capital con algún atributo de los préstamos (PD). Por el contrario, sería más eficiente disponer de un conjunto de curvas de riesgo, de modo que la carga de capital para una determinada exposición se reduzca cuando el capital económico sea escaso en relación a las oportunidades de préstamos. En un razonamiento similar, si se determina un nivel de confianza fijo (habitualmente, 99.9 para riesgo de crédito), ante una recesión, los préstamos no-fallidos incrementarán su riesgo (es decir, elevarán la PD) y las cargas de capital se elevarán. Sería conveniente fijar un alto nivel de confianza en las épocas de expansión (cuando el capital del banco es abundante) y trabajar con una curva de riesgo inferior en recesión, correspondiente a un nivel de confianza más bajo y una carga de capital reducida. Así será posible no sólo moverse dentro de una curva sino también de una a otra. 
A pesar de que las agencias externas sostienen que sus calificaciones responden a la evolución del riesgo fundamental, corrigiendo los factores cíclicos y, en ese sentido, reduciendo la prociclicidad, debe considerarse que los esquemas de rating diseñados para ser estables a lo largo del ciclo económico (semejantes a los de las agencias de evaluación) no elevarían la prociclicidad, pero aquellos que se condicionen a un momento concreto del ciclo sí.

Si los modelos internos son capaces de considerar los cambios en PD a lo largo del ciclo, los efectos no serán exagerados. En el caso de entidades que desarrollen modelos $\mathrm{VaR}$, que suelen reflejar evaluaciones en un momento puntual y con variables volátiles (precios de las acciones), los efectos cíclicos podrían ser significativos. Los enfoques de medición del riesgo crediticio ignoran pues la migración de los ratings, uno de los principales elementos cíclicos, ya que tanto los ratings internos como externos mejoran durante la expansión económica y se deterioran en la recesión.

El ciclo económico puede reflejarse en todos los componentes del riesgo (PD, LGD, EAD) y las correlaciones entre ellos. Dado que los sistemas de rating bancarios responden a cambios en el riesgo de default de los prestatarios, el capital requerido según el modelo IRB de Basilea-2 tenderá a aumentar cuando el ciclo económico sea recesivo, disminuyendo en el expansivo. Adicionalmente, en la medida que los bancos respondan a esta situación recortando (aumentando) el préstamo, los ciclos económicos se amplificarán.

Gordy y Howells (2004) proponen tres soluciones para solucionar la prociclicidad derivada del método IRB ${ }^{30}$ : i) adoptar metodologías de rating a lo largo del ciclo que eliminen el impacto del ciclo sobre el rating del prestatario, ii) alisar la función aplicada según IRB para reducir la sensibilidad de las cargas de capital a cambios en PD, iii) alisar directamente el resultado obtenido al aplicar la función IRB.

No obstante, algunos elementos del Acuerdo pretenden ya compensar dicha prociclicidad: aplanamiento de las curvas de capital,

30 Desde la perspectiva del pilar 3, el efecto de las tres opciones es distinto: la primera afecta negativamente a la comparabilidad temporal del capital requerido según IRB, la segunda al valor informativo del ratio de capital tanto temporalmente como entre entidades, y la tercera enfría la prociclicidad pero hace que los requisitos de capital sin alisar se infieran directamente del mínimo regulatorio. 
Evolución del proceso de regulación bancaria hasta

Basilea2: Origen, características y posibles efectos

estimación de PD al menos a medio plazo, solicitar capital adicional a través del pilar 2 (el pilar 1 no parece el más adecuado para solventar este problema, si pretende lograr su objetivo de vincular el capital requerido y perfil de riesgos), incorporación de un seguro de depósitos con primas basadas en el riesgo en lugar de requisitos de capital $^{31}$, o de una provisión dinámica que cubra el riesgo latente (Saurina Salas 2002). Además, en la actualidad la tendencia general de los bancos es mantener capital por encima del exigido, siendo éste la primera medida de absorción de la prociclicidad (Peura y Jokivuolle 2004).

También es posible desincentivar la prociclicidad si Basilea2 es capaz de fomentar un comportamiento forward-looking por parte de los gestores bancarios, de modo que sus decisiones durante una fase expansiva sean más racionales. Así, Jordan et al. (2003) argumentan que la sensibilidad al riesgo del Acuerdo puede animar a reconocer y corregir antes las inadecuaciones de capital, previniendo las caídas del capital que desencadenan dificultades crediticias. En este sentido, sería conveniente considerar dos modelos que caractericen el ciclo económico (en expansión y en recesión), presuponiendo que éste en parcialmente predecible (Pederzoli y Torricelli 2005).

\section{CONCLUSIONES}

La trayectoria seguida por la regulación bancaria hasta Basilea-2 sólo puede entenderse desde las peculiaridades del sector y su especial relevancia en la economía, siendo las reglas acerca del capital bancario el máximo exponente de dicha regulación.

En respuesta a los problemas financieros sufridos por varias entidades en las últimas décadas, el esquema regulatorio y el papel del supervisor han ido adaptándose de forma progresiva a las nuevas situaciones: la necesidad de un Acuerdo internacional como referente y la posterior decisión de modificarlo para responder a un nuevo contexto económico y a elementos que hasta entonces no se habían considerado así lo confirman.

31 Pennacchi (2005) comprueba que el impacto procíclico sobre los bancos de fijar primas de seguros de depósito basadas en el riesgo es menor que el que suponen los requisitos de capital. Así, es preferible permitir que tanto las primas del seguro como el capital requerido varíen durante el ciclo a fijar primas de seguros y variar tan sólo el capital. 
Conviene recordar en este punto que los acuerdos que emanan del Comité de Supervisión Bancaria de Basilea no tienen fuerza legal. Sin embargo, el cometido de esta organización desde su creación en 1978, ha sido mejorar la colaboración entre las autoridades de supervisión bancaria, convirtiéndose en un foro de debate para la resolución de problemas específicos de supervisión. De ahí han surgido normas de supervisión, especialmente relativas a la solvencia, en un esquema de participación de países y/o regiones tan significativas que sus regulaciones acaban siendo adoptadas y adaptadas, como ha ocurrido en el caso de la Unión Europea, EE.UU. o Japón.

La Unión Europa ha desarrollado un esquema similar al del Comité, emitiendo su propuesta de revisión de la Directiva Bancaria (2000/12/EC) y la Directiva de Adecuación de Capital (93/6/EEC) para introducir nuevos requisitos para bancos y empresas de inversión, en paralelo a la adopción progresiva de las normas internacionales de contabilidad desde el 1 de enero de 2005. Las Directivas respetan los contenidos de Basilea-2 pero los adaptan a las peculiaridades del caso europeo, especialmente en su aplicación a un variado tipo de entidades financieros, que abarcan diversos niveles de complejidad y tamaño, tanto en bancos como en empresas de inversión.

El calendario para la Unión Europea prevé que los modelos más sencillos que configuran el primer pilar comiencen a aplicarse desde el 1 de enero de 2007, al igual que los pilares segundo y tercero. Se aplaza para un año más tarde la utilización de metodologías avanzadas. Además, es posible seguir en el esquema del Acuerdo de 1988 durante 2007, a condición de comenzar aplicando los enfoques avanzados en el 2008. Esta flexibilidad es menor en el caso norteamericano, donde los bancos deberán optar entre mantenerse en el esquema actual o trabajar directamente con modelos avanzados. En este caso, los tres pilares entrarán en vigor al comenzar el 2008. En el caso japonés, los plazos de aplicación para modelos básicos y avanzados coinciden con el supuesto europeo, pero el segundo y tercer pilar no se aplicarán desde el principio, sino a partir del 31 de diciembre de 2007. Se observa pues, la dificultad añadida que esta diversidad de plazos y condiciones puede suponer para los bancos con actividad internacional. Es previsible, además, que la aplicación del Acuerdo se produzca a medio plazo en economías emergentes y en transición.

Pese al carácter abierto del nuevo Acuerdo y la multitud de posibilidades que ofrece en algunos casos, siguen sin resolverse 
Evolución del proceso de regulación bancaria hasta

Basilear: Origen, características y posibles efectos

determinadas cuestiones: el efecto procíclico que ya se achacó a su precedente, el definitivo papel del regulador como encargado de "aprobar" las cifras de capital derivadas del mero cálculo del pilar 1, los efectos sobre la competencia, la decisión de las entidades de dimensión media respecto al trabajo encaminado al desarrollo de modelos internos o su aplazamiento, la respuesta al caso concreto del riesgo operacional (de especial dificultad dado su carácter cualitativo y heterogéneo), la divulgación de más información de acuerdo a los requisitos del pilar 3, etc.

Deberá también valorarse la bondad del esquema regulatorio definido por Basilea-2 y que también caracteriza el proceso seguido actualmente por las compañías de seguros, en el desarrollo de Solvencia-2, un proyecto que sigue el esquema en tres pilares incorporado en Basilea.

Además de estos efectos, la puesta en práctica permitirá seleccionar aquellos modelos que resulten ser más eficientes, derivando en previsibles modificaciones de la redacción del Acuerdo recientemente aprobado. Como siempre, la aplicación conducirá a resultados mucho más concluyentes y a una evaluación efectiva del camino que la comunidad financiera acaba de emprender. Este camino, junto con el proceso de armonización contable internacional, se perfila como el reto más significativo a partir de ahora.

\section{BIBLIOGRAFÍA}

AKERLOF, G.A. (1970) "The market for 'lemons': quality uncertainty and the market mechanism", Quarterly journal of economics, 84, August, pp. 488-501.

AlLeN, L.; BALI, T. [en línea] (2004) "Cyclicality in catastrophic and operational risk measurements", www.gloriamundi.org/picsresources/ latb.pdf

-; SAUNDERS, A. (2004) "Incorporating systemic influences into risk measurements: a survey of the literature", J ournal of financial services research, vol. 26, $n^{\circ} 2$, pp. 161-192.

ALTMAN, E.I.; BHARATH, S.T.; SAUNDERS, A. (2002) "Credit ratings and the BIS capital adequacy reform agenda", Journal of banking \& finance, 26, pp. 909-921.

AYUSO, J.; PÉREZ, D.; SAURINA, J. (2004) "Are capital buffers pro-cyclical? Evidence from Spanish panel data", J ournal of financial intermediation, 13, pp. 249-264. 
Barajas, A.; Chaml, R.; Cosimano, T. (2005) Did the Basel Accord cause a credit slowdown in Latin America?, International Monetary Fund Working Paper 05/38.

BARRIOS, V.E.; BLANCO, J.M. (2003) "The effectiveness of bank capital adequacy regulation: a theoretical and empirical approach", J ournal of Banking \& Finance, 27, pp. 1935-1958.

BARTH, J.R.; CAPRIO Jr., G.; LEVINE, R. (2004) "Bank regulation and supervision: what works best?", Journal of financial intermediation, 13, pp. 205-248.

BASEl CommitTeE ON BANKING SuPerVISION (1988) "International convergence of capital measurement and capital standards", Bank for International Settlements, July, Basel.

- (1993) "The supervisory treatment of market risk. Consultative proposal by the BCBS", Bank for International Settlements, April, Basel.

- (1996) "Amendment to the capital accord to incorporate market risks", Bank for International Settlements, January, Basel.

- (1998) "Enhancing bank transparency", Bank for international Settlements, September, Basel.

- (1999a) "Capital requirements and bank behaviour: the impact of the Basel Accord", Bank for international Settlements, BCBS Working Paper $\mathrm{n}^{\circ} 1$, April, Basel.

- (1999b) "A new capital adequacy framework. Consultative paper, issued by the Basel Committee on Banking Supervision. Issued for comment by 31 March 2000", Bank for International Settlements, June, Basel.

- (2001a) "Consultative Document. The new Basel Capital Accord. Issued for comment by 31 May 2001", Bank for International Settlements, January, Basel.

- (2001b) "Consultative Document. Operational risk. Supporting document to the New Basel Capital Accord", Bank for International Settlements, January, Basel.

- (2003a) "The new Basel Capital Accord. Consultative Document", Bank for International Settlements, April, Basel.

- (2003b) "High level principles for the cross-border implementation of the New Accord", Bank for International Settlements, August, Basel.

- (2004a) "Consensus achieved on Basel II proposals", Bank for International Settlements, nota de prensa, 11 de mayo. 
- (2004b) "International Convergence of Capital Measurement and Capital Standards: a Revised Framework", Bank for International Settlements, June, Basel.

- (2004c) "Implementation of Basel II: Practical considerations", Bank for International Settlements, July, Basel.

Beattie, V.A.; Casson, P.D.; Sale, R.S.; MCKenzie, G.W.; SutCliffe, C.M.S.; TURNER, M.J. (1995) Banks and bad debts. Chichester: Wiley.

Berger, A.N.; HerRing, R.J.; Szegó, G.P. (1995) "The role of capital in financial institutions", Working paper 95-01, Wharton Financial Institutions Center.

BesANKO, D.; KANATAS, G. (1993) "Credit market equilibrium with bank monitoring and moral hazard", The review of financial studies, 6, pp. 213-232.

BHATTACHARYA, S.; THAKOR, A.V. (1993) "Contemporary Banking Theory", J ournal of Financial Intermediation, 3, pp. 2-50.

BIKHCHANDANI, S.; SHARMA, S. (2001) "Herd behavior in financial markets", International Monetary Fund Staff Papers, vol. 47, $n^{\circ} 3$, pp. 279-310.

BIKKER, J.A.; METZEMAKERS, P.A.J. (2005) "Bank provisioning behaviour and procyclicality", J ournal of international financial markets, institutions \& money, 15, pp. 141-157.

BLUM, J. (1999) "Do capital adequacy requirement reduce risks in banking?", J ournal of Banking \& Finance, 23, pp. 755-771.

Boot, A.; Greenbaum, S. (1993) "Bank Regulation, Reputation and Rents: Theory and Policy Implications", en MAYER, C.; VIVES, X. (eds.), Capital Markets and Financial Intermediation, pp. 69-88, New York: Cambridge University Press.

BorIO, C.; FURFINE, C.; LOWE, P. (2001) "Procyclicality of the financial system and financial stability: issues and policy option", en Marrying the macro- and micro-prudential dimensions of financial stability, Bis Papers No.1, 1-57.

CALEM, P.S.; RoB, R. (1996) "The impact of capital-based regulation on bank risk-taking: a dynamic model", Federal Reserve Board, Paper 1996-12, finance and economic discussion series.

CANTOR, R. (2001) "Moody's investors service response to the consultative paper issued by the Basel Committee on Banking supervision «A new capital adequacy framework»", J ournal of Banking \& Finance, 25, pp. 171-185. 
Catarineu-Rabell, E.; Jackson, P.; Tsomocos, D.P. (2003) "Procyclicality and the new Basel Accord bank's choice of loan rating system", Bank of England, Working Paper no. 181.

CHIURI, M.C.; FERRI, G.; MAJNONI, G. (2002) "The macroeconomic impact of bank capital requirements in emerging economies: past evidence to assess the future", J ournal of Banking \& Finance, 26, pp. 881-904.

ChORAFAS, D.N. (2004a) Operational risk control with Basel II. Basic principles and capital requirements. Oxford: Elsevier.

- (2004b) Economic capital allocation with Basel II: Cost, benefit and implementation procedures. Oxford: Elsevier.

DANíELSSON, J. [en línea] (2002) "On the feasibility of risk based regulation", www.RiskResearch.org.

-; Embrechts, P.; Goodhart, C.; Keating, C.; Muennich, F.; Renault, O.; SONG SHING, H. (2001) "An academic response to Basel II", Financial Markets Group Special Paper No. 130.

DECAMPS, J.P.; ROCHET, J.C. \& B. ROGER (2004) "The three pillars of Basel II: optimizing the mix", J ournal of Financial Intermediation, vol. 13, issue 2, pp. 132-155.

DEWATRIPONT, M.; TIROLE, J. (1993) "Efficient Governance Structure: Implications for Banking Regulation". en MAYER, C.; VIVES, X. (eds.), Capital Markets and Financial Intermediation. New York: Cambridge University Press.

-; - (1995) The prudential regulation of banks. MIT Press.

DeYoung, R.; HugheS, J.P.; MOON, C. (2001) "Efficient risk-taking and regulatory covenant enforcement in a deregulated banking industry", J ournal of Economics \& Business, 53, pp. 255-282.

DIAMOND, D.W.; DYBVIG, P. (1983) "Bank runs, deposit insurance and liquidity", J ournal of Political Economy, 91 (3), pp. 401-419.

DowD, K. (1999) "Does asymmetric information justify bank capital adequacy regulation?", Cato J ournal, vol. 19, n¹, spring/summer, pp. 39-47.

Estrella, A. (2004) "The cyclical behaviour of optimal bank capital", J ournal of Banking \& Finance, 28, pp. 1469-1498.

EvanofF, D.D.; WALL, C.D. (2000) "Subordinated debt and bank capital reform", Working paper 2000-07, Federal Reserve Bank of Chicago.

FlanNery, M.J. (1989) "Capital Regulation and Insured Banks' Choice of Individual Loan Default Risks", J ournal of Monetary Economics, vol. 24, pp. 235-58. 
-; RANGAN, K.P. [en línea] (2002) "Market forces at work in the banking industry: evidence from the capital buildup of the 1990s", Working paper Financial intermediation research society, www.finirs.org/ papers/02/0201.html.

FREIXAS, X.; SAURINA, J. (2004) "Teoría y práctica de la regulación bancaria", Moneda y Crédito, 218, pp.111-157.

FURFINE, C. (2001) "Bank portfolio allocation: The impact of capital requirements, regulatory monitoring, and economic conditions", J ournal of Financial Services Research, vol. 20, issue 1, pp. 33-56.

FURLONG, F.T.; KEELEY, M.C. (1989) "Capital Regulation and bank risktaking: a note", J ournal of Banking \& Finance, 14, pp. 883-891.

Gallati, R. (2003) Risk management and capital adequacy. New York: McGraw-Hill.

García Higuera, C. (2001) Capital bancario. Gestión estratégica de los fondos propios en las entidades de crédito. Madrid: Instituto superior de técnicas y prácticas bancarias.

GEHRIG, T. (1995) "Capital Adequacy Rules: Implications for bank's risktaking", Swiss J ournal of Economics and Statistics, vol. 131(4/2), pp. 747-764.

GonZÁlEZ MOTA, E. (2005) "Prociclicidad, volatilidad financiera y Basilea II", Estabilidad Financiera, 8, pp. 153-161, Banco de España, mayo.

GoRDY, M.B.; HowelLS, B. (2004) "Procyclicality in Basel II: Can we treat the disease without killing the patient?", Board of Governors of the Federal Reserve System.

GRIeP, C.; De Stefano, M. (2001) "Standard \& Poor's official response to the Basel Committee's proposal", J ournal of Banking \& Finance, 25, pp. 149-169.

GUEYIE, J.P.; LAI, V.S. (2003) "Bank moral hazard and the introduction of official deposit insurance in Canada", International Review of Economics and Finance, 12, pp. 247-273.

HALL, B.J. (1993) "How has the Basle Accord affected bank portfolios?", J ournal of the J apanese and international economies, 7, pp. 408-440.

HANCOCK, D.; LAING, A.J. \& WILCOX, J.A. (1995) "Bank capital shocks: dynamic effects and securities, loans, and capital", J ournal of Banking and Finance, 19, pp. 661-677.

HERRING, R.J. (2004) "The subordinated debt alternative to Basel II", J ournal of financial stability, vol. 1, issue 2, pp. 137-155. 
HOGgarth, G.; ReIS, R.; SAPORTA, V. (2001) "Costs of banking system instability: some empirical evidence", Working paper Bank of England.

Honohan, P.; KLINGEBIEL, D. (2000) "Controlling fiscal costs of banking crises", The World Bank.

Iglesias-SARRIA, C.; VARGAS, F. (2004) "El Nuevo Acuerdo de Capital 'Basilea II' y su transposición europea: el proceso y la implementación", Estabilidad Financiera, 7, noviembre, pp. 9-57. Banco de España.

ILLING, M.; PAULIN, G. (2004) "The new Basel Capital Accord and the cyclical behaviour of bank capital", Bank of Canada, Working paper $\mathrm{n}^{\circ}$ 30, Agosto.

ITO, T.; SASAKI, Y.N. (2002) "Impacts of the Basle Capital Standard on Japanese banks' behaviour", J ournal of the J apanese and International Economies, 16, pp. 372-397.

JONES, D. (2000) "Emerging problems with the Basel Capital Accord: Regulatory capital arbitrage and related issues", J ournal of Banking \& Finance, 24, pp. 35-58.

-; MINGO, J. (1999) "Credit risk modelling and internal capital allocation processes: implications for a models-based regulatory bank capital standard", J ournal of Economics and Business, 51, pp. 79-108.

Jordan, J.; Peek, J.; Rosengren, E. (2003) "Credit risk modelling and the cyclicality of capital", Federal Reserve Bank of Boston, Working Paper, octubre.

KAHANE, Y. (1977) "Capital adequacy and the regulation of financial intermediaries", J ournal of Banking \& Finance, vol.1, n² 2, pp. 207-218.

KASHYAP, A.K.; STEIN, J.C. (2004) "Cyclical implications of the Basel II capital standards", Economic Perspectives, Federal Reserve Bank of Chicago, 10, pp. 18-31.

KAUFMAN, G.G. (1992) "Capital in banking: past, present and future", J ournal of financial services research, 5, pp. 385-402.

- (1996) "Bank failures, systemic risk, and bank regulation", Cato J ournal, vol. 16, 1, Spring/summer.

KIM, D.; SANTOMERO, A.M. (1988) "Regulation of bank capital and portfolio risk", J ournal of Finance, 43, pp. 1235-44.

KIRSTEIN, R. (2001) "The New Basle Accord, internal ratings, and the incentives of banks", Center for the Study of Law and Economics, Discussion Paper 2000-06. 
KoEHN, M.; Santomero, A.M. (1980) "Regulation of bank capital and portfolio risk", The journal of finance, vol. 35, 5, pp. 1235-1244.

KONISHI, M.; YASUDA, Y. (2004) "Factors affecting bank risk taking: evidence from Japan", J ournal of Banking \& Finance, 28, pp. 215-232.

KOOPMAN, S.J.; LUCAS, A.; KLAASSEN, P. (2005) "Empirical credit cycles and capital formation", J ournal of Banking \& Finance, 29, pp. 3159-3179.

KWAN, S.; EISENBEIS, R.A. (1997) "Bank risk, capitalization and inefficiency", Journal of financial services research, vol. 12 (2/3), pp. 117-131, octubre.

LEVINE, R. (2002) "Bank-based or market-based financial systems: which is better?", J ournal of financial intermediation, 11, pp. 398-428.

LLEWELLYN, D.T. (2002) "An analysis of the causes of recent banking crises", The European J ournal of Finance, 8, pp. 152-175.

LOWE, P. (2002) "Credit risk measurements and procyclicality", BIS Working Papers $n^{\circ} 116$, September.

MATTEN, C. (2000) Managing bank capital: capital allocation and performance measurement. Chichester: John Wiley.

MÉNDEZ DEL Río, M. [en línea] (2003) "The new basel capital accord work progress", seminario BBVA conferencia en Washington, 14 de enero, www.iadb.org/sds/IFM/publication/gen_495_3230_s.htm.

MONTGOMERY, H. (2005) "The effect of the Basel accord on bank portfolios in Japan", J ournal of Japanese and international economies, 19, pp. 24-36.

OATLEY, T. (2001) "The dilemmas of international financial regulation", Regulation Magazine, vol. 23, 4, Spring, pp. 36-39.

PeCCHENINO, R.A. (1998) "Risk averse bank managers: exogenous shocks, portfolio reallocations and market spillovers", Journal of Banking \& Finance, 22, pp. 161-174.

Pederzoli, C.; Torricelli, C. (2005) "Capital requirements and business cycle regimes: forward-looking modelling of default probabilities", J ournal of Banking \& Finance, 29, pp. 3121-3140.

PENNACCHI, G. (2005) "Risk-based capital standards, deposit insurance, and procyclicality", J ournal of financial intermediation, 14, pp. 432-465.

Peura, S.; Jokivuolle, E. (2004) "Simulation based stress tests of banks' regulatory capital adequacy", J ournal of Banking \& Finance, vol. 28 (8), pp. 1801-1824. 
RIME, B. (2001) "Capital requirements and bank behaviour: empirical evidence for Switzerland", J ournal of Banking \& Finance, 25, pp. 789805.

ROCHET, J.C. (1992) "Capital requirements and the behaviour of commercial banks", European Economic Review, 26, pp. 1137-1178.

- (2003) "Rebalancing the 3 Pillars of Basel 2", Economic Policy Review, vol. 10 , issue 2 , pp. 7-21.

RodRíGUEZ, L.J. (2003) "Banking stability and the Basle Capital Standards", Cato J ournal, Spring/summer, vol. 23 (1), pp. 115-126.

SaIdenberg, M.; Schuermann, T. [en línea] (2003) "The new Basel Capital Accord and questions for research", Working Paper The Wharton School, No. 03-14: fic.wharton.upenn.edu/fic/papers/03/0314.pdf.

SANTOS, J.A.C. (1999) "Bank capital and equity investment regulations", J ournal of Banking \& Finance, 23, pp. 1095-1120.

- (2000) "Bank capital regulation in contemporary banking theory: a review of the literature", BIS Working Paper No. 90, September, Basel.

SAURINA SALAS, J. (2002) "Solvencia bancaria, riesgo de crédito y regulación pública: el caso de la provisión estadística española", Hacienda Pública Española/ Revista de Economía Pública, 161-2, pp. 129-150.

SHARPE, W.F. (1978) "Bank capital adequacy, deposit insurance and security values", J ournal of financial and quantitative analysis, vol. 13, pp. 701-718.

SIRONI, A.; ZaZzARA, C. (2003) "The Basel Committee proposals for a new capital accord: implications for Italian banks", Review of financial economics, 12, pp. 99-126.

Tsomocos, D.P. (2003) "Equilibrium analysis, banking and financial instability", J ournal of mathematical economics, 29, pp. 619-655.

YOUNG, B.; ASHBY, S. (2001) "The strategic importance of insurance as a mitigant for operational risk", en Advances in Operational Risk. Firmwide issues for financial institutions. Londres: Andersen Risk Books.

ZAKRAJSEK, E.; CARPENTER, S.B.; WHITESELL, W.C. (2001) "Capital Requirements, Business Loans, and Business Cycles: An Empirical Analysis of the Standardized Approach in the New Basel Capital Accord", November, FEDS Working Paper $n^{\circ}$ 2001-48. 